\title{
Chapter 3 \\ Science During Crisis: The Application of Interdisciplinary and Strategic Science During Major Environmental Crises
}

\author{
Gary E. Machlis and Kristin Ludwig
}

\subsection{Introduction}

On the French Caribbean island of Martinique in late April 1902, La Commission Sur le Volcan (Commission on the Volcano) met to decide a course of action. The island's Mt. Pelée was sending steam and smoke skyward, the smell of sulfur was in the air, and swarms of insects were moving down the mountain into neighboring cane fields. Frequent earthquakes and a thin layer of ash had set the population (particularly in the coastal city of St. Pierre) on edge and created a sense of crisis. The Commission included doctors, pharmacists, and science teachers, all appointed by the Governor. They discussed the potential of an eruption and what precautions, including evacuation, should be considered. The island was in the midst of general elections, complicating a response. After several meetings, the Commission made its decision, and announced "There is nothing in the activity of Pelée that warrants a departure from St. Pierre...the safety of St. Pierre [is] absolutely assured." Posters were placed throughout the town announcing the public's safety.

On May 8 Mt. Pelée erupted with an incandescent, high-velocity ash flow, associated hot gases, and dust - a pyroclastic flow of great destructive power. The cloud of hot ash and gases raced into St. Pierre at an estimated speed of $160 \mathrm{~km} / \mathrm{h}$ (Fig. 3.1).Approximately 30,000 residents (including all members of the Commission) died within minutes, leaving only two survivors. One eyewitness described the scene:

The whole side of the mountain seemed to gape open, and from the fissure belched a lurid whirlwind of fire, which wreathed itself into vast masses of flame as, with terrible speed, it

\author{
G.E. Machlis $(\square)$ \\ School of Agricultural, Forest, and Environmental Sciences, Clemson University, \\ 260 Lehotsky Hall, Clemson, SC 29634-0735, USA \\ e-mail:machlis@clemson.edu \\ K. Ludwig \\ Natural Hazards Mission Area, U.S. Geological Survey, \\ 12201 Sunrise Valley Drive - MS905, Reston, VA 20192, USA
}




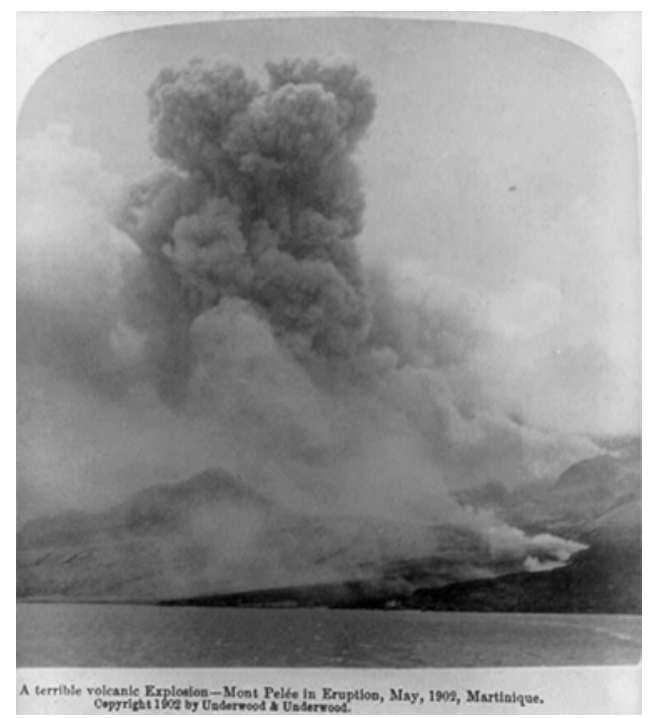

Fig. 3.1 Photograph of Mt. Pelée May 7, 1902 (Photograph by Angelo Helprin, survivor. St. Pierre, Martinique, French West Indies. 1902 collection, Prints \& Photographs Division, Library of Congress, LC-USZ62-47617. http://www.loc.gov/pictures/item/2006689820/)

descended on the doomed town. Before the true extent of the peril could be grasped, the fiery mass swept like a river over the town, and thrusting the very waters of the sea before it, set the ships ablaze. (Fermor 1950)

Environmental crises require decisions, and such fateful decisions require science. The distinctive and increasingly critical role of interdisciplinary science including the physical, biological, and social sciences - during environmental crises is the topic of this chapter.

The structural processes of science have long been studied and debated (see for example Kuhn's The Structure of Scientific Revolutions, 1962, and commentary by Sarder 2000). However, the distinctive context of science during crisis events - and how best to conduct and deliver "crisis" science - has largely been left to historians (such as Richard Rhodes in The Making of the Atomic Bomb, 1986), scientists engaged in such work (Freudenburg and Gramling 2011; Machlis and McNutt 2011; Lubchenco et al. 2012), and critics focused on specialized or unusual cases (Taleb 2007). Crises vary in intensity, consequence, and scope - and range from events of war and security to health and public safety. They are often reflected in the strange and vivid metaphors surrounding crisis management: "black swans," "wicked problems," "acute events," and so forth (Rittel and Webber 1973; Taleb 2007; Brown et al. 2010).

Historical and contemporary experience suggests that science - including the physical, biological, and social sciences - plays an increasingly critical role in governmental and institutional responses to major environmental crises such as those caused by natural hazards or man-made disasters. Recent examples include major western US wildfires (2009), the Deepwater Horizon oil spill (2010), the Fukushima nuclear plant failures (2011), and Hurricane Sandy (2012). 
Understanding the structural processes of science during environmental crises may have considerable value in developing best practices for the conduct and delivery of science during crisis. In addition, focusing on the potential role of social science during these events is critical to social science practitioners and the broader community of scientists, decision makers, and emergency responders who use social science to inform crisis response. There is also a substantial need to better define the roles of strategic and tactical science during crises. While tactical science focuses on immediate challenges and technical solutions, strategic science focuses on the longer-term issues of response and recovery, and considers longer chains of cascading consequences than is typical in tactical approaches (Machlis and McNutt 2010, 2011).

In this chapter, we explore the role and significance of science - including all disciplines and focusing attention on the social sciences - in responding to the needs of emergency response and recovery during major environmental crises. First, we examine the role of science during two recent major environmental crisis events the Deepwater Horizon oil spill (2010) and Hurricane Sandy (2012). Second, we briefly review several specific examples of social science applied to environmental crisis events - Cyclone Sidr in Bangladesh (2007), the Puerto Aysen earthquake in Chile (2007), and Hurricane Katrina in the US (2005). Third, we identify several distinctive characteristics of strategic science during environmental crises. Finally, we describe a modest research agenda to advance the role of science during environmental crises.

\subsection{Science During Crisis: Two Examples}

\subsubsection{0: Deepwater Horizon Oil Spill}

On April 20, 2010, the Deepwater Horizon drilling platform catastrophically exploded and later collapsed into the sea, killing 11 men and spilling over 4.9 million barrels of oil into the Gulf of Mexico, making it one of the worst man-made environmental disasters in US history (Mabus 2010; McNutt et al. 2012). Compared to other oil spills, Deepwater Horizon was unprecedented in its complexity and impact. At its peak, oil and tar balls contaminated the coastlines of all five Gulf states and led to the closure of 229,271 sq. $\mathrm{km}$ of federal waters to fishing (Mabus 2010). Response efforts included more than 47,000 personnel, 7,000 vessels, 120 aircraft, and the participation of scores of federal, state, and local agencies, universities, and non-governmental organizations (Mabus 2010).

In contrast to surface spills such as Exxon Valdez in Alaska (1989) or the Santa Barbara oil spill (1969), the Deepwater Horizon spill occurred at depth - crude oil flowed from a broken drill pipe approximately $1,500 \mathrm{~m}$ below the surface of the water. The extreme depth of the spill introduced new challenges in both engineering and environmental conditions that had to be overcome. Response crews needed ships with remotely operated vehicles equipped with sophisticated sensors, cameras, and robotic arms to navigate the wreckage and access the well. Engineers had 
to rapidly devise new capping devices to kill the well, which were thwarted by the formation of gas hydrates - crystals of methane ice that only form at depth clogging the devices during several deployment attempts. Oil spilled into the Gulf continuously for nearly three consecutive months, polluting a three-dimensional area that extended vertically from the seafloor to the surface, and laterally across the Gulf, impacting the people, the environment, and the economy of the region.

Science played a vital role in stopping and responding to the spill. Because of the extreme complexity of the disaster, researchers and engineers from across academia, the federal government, and the private sector were called on to contribute their expertise in fields such as oceanography, geology, underwater engineering, physics, public health, and ecology (Lubchenco et al. 2012). Teams of scientists and the leaders of major federal science agencies including the Department of Energy, the US Geological Survey, and the National Oceanic and Atmospheric Administration (NOAA) were stationed at or near Incident Command centers established throughout the Gulf. Tactical science response efforts included geochemical "fingerprinting" of the oil, calculating the rate of flow from the broken pipe, and modeling the surface migration of oil using information on currents in the Gulf. The National Science Foundation awarded over 11 million dollars through its Rapid Response grants to research the spill.

Social science research was ongoing during the spill (April-September 2010), though it was fragmented, sometimes ad hoc, and largely peripheral to the engineering, toxicology, and ecological research that formed the core of the scientific response. While the Natural Resources Damage Assessment (NRDA) mandated the documentation of human health, social impacts, economic impacts, and cultural resource damage, this work often lagged behind other NRDA needs. Later, in a post-incident review of science conducted during the crisis, Lubchenco et al. (2012) called for a "greater emphasis on social science data collecting including adequate baselines, to understand costs to the region and the nation of oil spill disasters" in the future.

During the crisis, the unplanned and sporadic nature of on-the-ground social science led to specific topics receiving significant attention. An example is the research on the psychological impacts of the spill. Grattan et al. (2011) and Morris et al. (2013) used a community-based participatory model to perform standardized assessments of psychological distress, comparing populations in communities directly and indirectly impacted by the spill. They found no significant differences: residents in both communities displayed clinically significant depression and anxiety. Abramson et al. (2010) focused on the impact of the spill on children in the region, and found heightened mental health distress. Lee and Blanchard (2012) found, interestingly, that community attachment associated with higher levels of anxiety and fear, based on data collected in three Louisiana parishes during the spill.

During the spill, there were numerous calls for interdisciplinary approaches for dealing with the spill, its environmental and socioeconomic impacts, and the need to bolster resilience of affected communities (see for example Levy and Gopalakrishnan 2010). One significant response was scenario-building conducted by the Department of the Interior's (DOI) experimental Strategic Sciences Working Group (SSWG), 


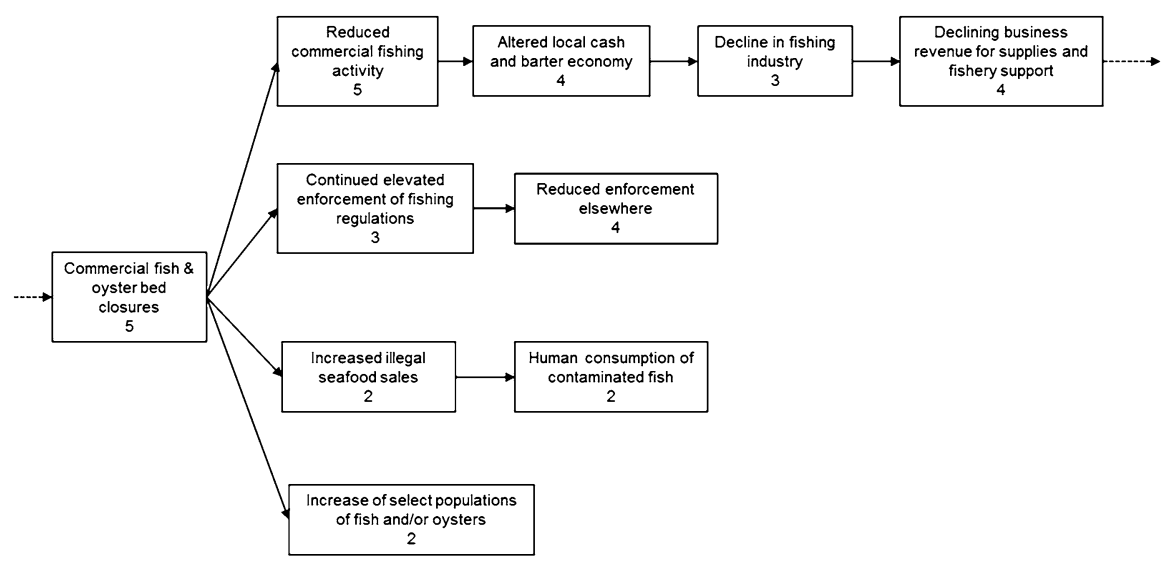

Fig. 3.2 A segment of one of the scenarios developed by the SSWG for the Deepwater Horizon oil spill. This segment shows the cascading effects of commercial fish and oyster bed closures (Department of the Interior 2012)

which analyzed the cascading consequences of the spill to inform decision-makers on near-term and long-term impacts (Machlis and McNutt 2010, 2011).

The SSWG was established quickly and included both federal and non-federal ecologists, social scientists, oceanographers, and other disciplinary experts. The SSWG worked extensively to create "chain of consequences" scenarios that included both biophysical and socioeconomic impacts (Department of the Interior 2010). Using the human ecosystem model (Machlis et al. 1997) as an organizing framework, and qualitatively assessing uncertainties, the SSWG created several scenarios and briefed DOI leadership on findings several times during the crisis. Figure 3.2 illustrates a small segment of one of the scenarios, focusing on commercial fishing and oyster bed closures. The numbers in the figure reflect the uncertainties associated with each consequence, with 5 being certain and lower numbers reflecting less certainty.

In September 2010, the spill officially ended when two relief wells enabled the well to be sealed. British Petroleum (BP), which had contracted the Deepwater Horizon platform, later committed $\$ 500$ million in research funds to be spent over a 10-year period to study the aftermath of the spill. An additional $\$ 350$ million from the $\$ 4$ billion settlement between BP and the federal government was given to the National Academy of Sciences to establish a new program focused on human health and ecosystem science of the Gulf of Mexico to be spent over a 30-year period (Shen 2012).

Even with the tremendous efforts of the scientific community to deliver critical information to the response, the Deepwater Horizon oil spill highlighted the need to improve coordination between agencies and the scientific community for ensuring efficient, innovative, and thoughtful response to environmental crises. This necessarily includes coordinated social science. As one report stated, "there is no national lead entity coordinating the mobilization of science assets across federal agencies 
and within the broader science community"(Consortium for Ocean Leadership 2010). While the National Response Framework defines the responsibilities of each federal agency for responding to a disaster, lessons learned from Deepwater Horizon suggest that new and/or improved organizational structures are necessary to facilitate the mobilization of the scientific community to aid response, and this continues to be a fertile area for innovations in science policy (e.g., Nature 2010).

\subsubsection{2: Hurricane Sandy}

In October 2012, Hurricane Sandy advanced toward the eastern seaboard of the United States. At the time of landfall near Atlantic City, New Jersey (NJ) on October 29 , Hurricane Sandy measured over 1,770 km in wind field diameter and was classified as a post-tropical storm (NOAA 2012; Blake et al. 2013). Combining with a nor'easter, Hurricane Sandy affected 17 states, producing storm surges of up to $2.6 \mathrm{~m}$, high precipitation including nearly $1 \mathrm{~m}$ of snow in areas of Maryland and West Virginia, and over 8.5 million households without power (Department of Energy 2012; Blake et al. 2013; US Geological Survey 2013).

Multiple dimensions of Sandy have required - and continue to require - tactical interdisciplinary science to support response efforts. Atmospheric scientists and meteorologists played a critical role in monitoring and assessing the formation and evolution of Sandy as it moved through the Caribbean, making landfall in Cuba before slowly progressing northward to pick up speed again before making its second landfall in New Jersey (Blake et al. 2013). Hydrologists deployed over 150 stream gauges to monitor storm surge while oceanographers evaluated potential damage to protective dunes and barrier islands (US Geological Survey 2013). In the aftermath of the storm, engineers were called upon to assess structural damage caused by flooding and wind. Public health experts, toxicologists, and chemists continue to assess health threats posed by mold in flooded houses, asbestos released from destroyed buildings, and other contaminants mobilized during fires that broke out during the storm.

Beginning days before Sandy's landfall and during the storm, social science efforts focused on providing necessary psychological and mental health services to the affected region. FEMA and American Red Cross deployed mental health professionals to the area days before the storm in preparation for supporting the citizens of the affected area. In the aftermath of the storm, multiple organizations launched social science studies to assess different dimensions - ranging from post-traumatic stress to the use of social media - of the storm's impacts on the social fabric of the region. FEMA awarded $\$ 82$ million to the state of New York to "deliver immediate mental health outreach, crisis, and education services" to 200,000 individuals in the region through its Immediate Services Crisis Counseling Assistance and Training Program (Sederer 2012). The Pew Research Center Project for Excellence in Journalism analyzed the public's use of social 
media from October 29-31, 2012 to examine how individuals interacted with one another and with news and information. The study found that "fully $34 \%$ of the Twitter discourse about the storm involved news organizations providing content, government sources offering information, people sharing... eye witness accounts, and still more passing along information posted by others" (Pew Research Center's Project for Excellence in Journalism 2013). At the organizational scale, one study examined the development of new partnerships in disaster relief operations, using Sandy as a case study and showing that $66 \%$ of the partnerships that were relied on during Sandy response were new (Coles and Zhuang 2013). Other ongoing social science studies have examined how volunteer organizations have played a critical role in stabilizing communities, and how the mental and physical stress of disruption and displacement may impact local citizens and health care providers.

In the aftermath of Hurricane Sandy, strategic science was used to support recovery efforts. In January 2013, the Secretary of the Interior directed the Strategic Sciences Group (SSG, formerly the Strategic Sciences Working group described above) to stand up a crisis science team to support the Department's role on the cabinet-level Hurricane Sandy Rebuilding Task Force. In response, the SSG assembled a team of experts from government, academia, and non-governmental institutions to develop scenarios for the Task Force. The team was to examine the short- and long-term impacts of Hurricane Sandy and future major storms (such as another major hurricane) on the ecology, economy, and people of the affected New York/ New Jersey region.

The SSG's Operational Group Sandy identified 13 primary or "first-tier" consequences of Sandy on coastal communities and ecosystems - from ecological change and changes in coastal geomorphology to altered storm preparedness and response activity and altered perception of risk (Department of the Interior 2013). Together, these consequences and their cascading consequences span a broad and complex range of environmental, economic, and social effects. Similar to the work completed during the Deepwater Horizon oil spill, the Hurricane Sandy scenarios used the human ecosystem model as an organizing framework; the scenarios are interdisciplinary and the impacts on the environment, infrastructure, and society are integrated throughout the scenarios.

One example of the SSG's work is shown in Fig. 3.3, which illustrates the cascading consequences resulting from Hurricane Sandy's flood damage to the built environment. This chain of consequences shows multiple dimensions of this damage, including the creation of hazardous and non-hazardous debris, new challenges in transportation, and downstream impacts to the local economy.

Using the results of the scenario, the SSG identified potential interventions, defined as institutional actions that support recovery and increase the resilience of the coupled human-natural system to future storms. The 17 interventions included several recommendations to bolster research in different areas, including ecosystem services, environmental contamination, social services, and risk education and communication (Department of the Interior 2013). 


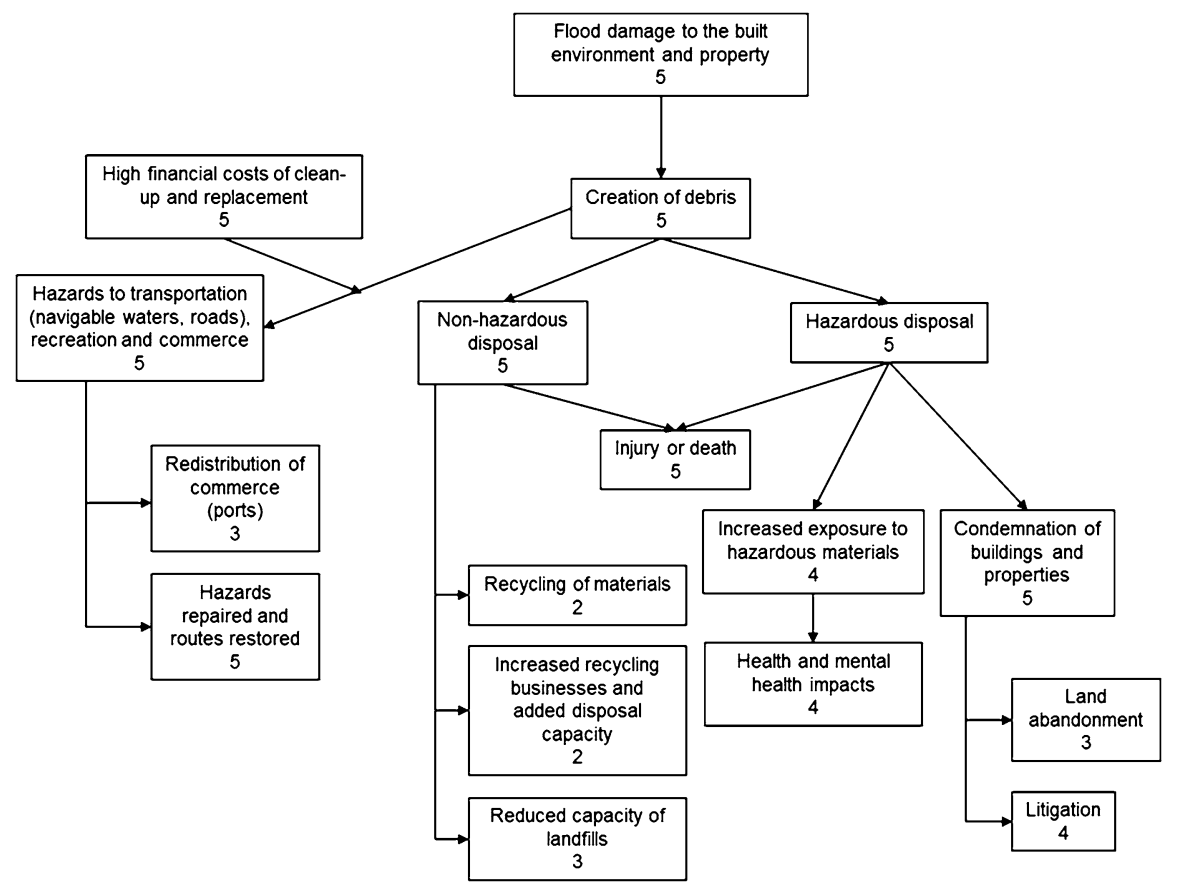

Fig. 3.3 Example chain of consequences from the SSG's Hurricane Sandy scenarios, showing the cascading consequences resulting from flood damage to the built environment in coastal communities. The numbers in the figure reflect the uncertainties associated with each consequence, with 5 being certain and lower numbers reflecting less certainty (Department of the Interior 2013)

\subsection{Examples of Social Science During Environmental Crisis Events}

Social science played a role in both of the major environmental crises described above. In these events and other crises, the social sciences (particularly but not uniquely sociology of risk, decision sciences, and community sociology) have contributed to both science during the crises and in the immediate aftermath as emergency response and recovery is underway. In many cases the research led to specific recommendations for action to improve crisis response. Several examples follow.

In 2007, Bangladesh was devastated by Tropical Cyclone Sidr, a Category 4 storm that killed 3,406 people and displaced or affected 27 million persons. A study by Paul (2012) examined factors that led to the resident's response to evacuation orders; the range of response is compelling, with only one-third of respondents evacuating to shelters. Policy recommendations to improve response during the crisis include expanded outreach programs, additional shelters, and evacuation drills.

From December 2006 to April 2007, the small Chilean town of Aysen (population 15,000) experienced intense seismic activity. Thousands of tremors were detected in the area, building up to a large earthquake on April 21, 2007. Though the 
earthquake itself was not a major event (magnitude 6.2), it did cause massive landslides, which in turn created localized tsunami waves that led to the death of 10 residents. During the seismic activity period, a parallel socio-political crisis developed, as controversy arose regarding the "decisions and best-suited measures required to prevent a potential disaster." A study by Soule (2012) reported on the factors that led to the socio-political crisis, which was centered on the perception (and eventual realization) of an imminent disaster, and makes recommendations for improving risk management as a result. Soule concludes that these findings "must be connected to a broader tendency to reject technocratic and centralized risk management" and calls for the incorporation of social science information during the assessment and decision making stages of risk management.

Hurricane Katrina made US landfall in Louisiana on August 29, 2005 as a large Category 3 hurricane. The levee system protecting New Orleans was breached, and over $75 \%$ of the city and nearby parishes were flooded. The storm (and subsequent flooding) led to 1,833 deaths and over $\$ 81$ billion dollars in property damage. A relatively large social science literature has emerged about the event, much of it based on data collected during or immediately after the crisis. For example, Millin et al. (2006) examined disaster medical assistance in both Mississippi and a volunteer site near New Orleans. Treatment of chronic disease, primary health care and routine emergency care not related to the hurricane were the most common needs. The authors suggested that in addition to acute medical needs, "disaster planners should prepare to provide primary health care, administer vaccinations, and provide missing long-term medications."

Vu and Van Landingham (2012) took advantage of survey work done just weeks prior to Hurricane Katrina, and were able to conduct a pre- and post-disaster assessment of physical and mental health consequences for working-age Vietnamese immigrants to New Orleans. The researchers located and re-assessed more than two-thirds of the original study cohort. They found statistically significant declines in physical and mental health status after the first anniversary of the storm, and substantial recovery by the second anniversary. Recovery varied by a number of key sociological variables (such as occupational type and marital status), and the authors suggested the results "present clear opportunities for targeted interventions."

\subsection{Distinctive Characteristics of Science During Environmental Crises}

The examples presented reveal the importance of science during environmental crises. In addition to traditional discipline-focused tactical research, the need and opportunity for interdisciplinary strategic science is intensified during such crises: decision makers need to quickly understand the impacts on coupled natural-human systems, the uncertainties and limitations that surround findings and analysis, the cascading consequences of the event, and an accurate sense of place that links the science to "on-the-ground" (or in the water) realities associated with a specific crisis event, time, and place. 
Hence, the application of strategic science during environmental crises has several distinctive characteristics that are essential requirements if it is to be useful to decision makers. Many of these characteristics may also be relevant to crises other than environmental. With all of these, it is critical to stress that science during crisis can only be effective when all relevant disciplines of science - the physical, biological, and social are fully integrated and actively engaged. Six key characteristics are described below.

\subsubsection{The Importance of Coupled Human-Natural Systems}

Science during environmental crises benefits from recognizing the need to evaluate and respond to the crisis using a systems approach, where consequences such as dune erosion during a hurricane are not just interpreted as an environmental change and loss of habitat, but as a storm consequence that may also compromise the safety of houses (and thereby households) that rely on these natural storm buffers for protection. Models of coupled human-natural systems are especially valuable to such strategic science.

One example (among many) is the human ecosystem model (Machlis et al. 1997, see Fig. 3.4) applied during the Deepwater Horizon oil spill (Department of the Interior 2010, 2012) and most recently Hurricane Sandy. It describes a reasonably detailed coupled human-natural system, including both biophysical and sociocultural variables, as well as flows of individuals, energy, nutrients, information, materials, capital, and information. The human ecosystem model originated in the 1997 paper entitled "The human ecosystem as an organizing concept" that was published in two parts in the journal Society and Natural Resources. A modest commentary has appeared (see for example Rudel 1999), and applications have included the National Science Foundation's Long Term Ecological Research Program in Baltimore, MD, a National Oceanic and Atmospheric Administration training program, and the United Nations Environmental Program on Sustainability. Models like these are essential for achieving a holistic approach to assessing impacts and anticipating cascading consequences, particularly during crises where the full range of consequences is both unknown and uncertain.

\subsubsection{The Challenge of Collaboration and Interdisciplinary Teams}

During non-crisis times, scientific research is conducted by individual principal investigators and/or teams of scientists. Research teams are often multi-institutional and in most cases, researchers collaborate with colleagues they have worked with in the past or with whom they have some pre-existing relationship. New collaborations are often formed through the long-term exchange of knowledge and ideas at regularly scheduled workshops, academic conferences, and peer-reviewed publications. 


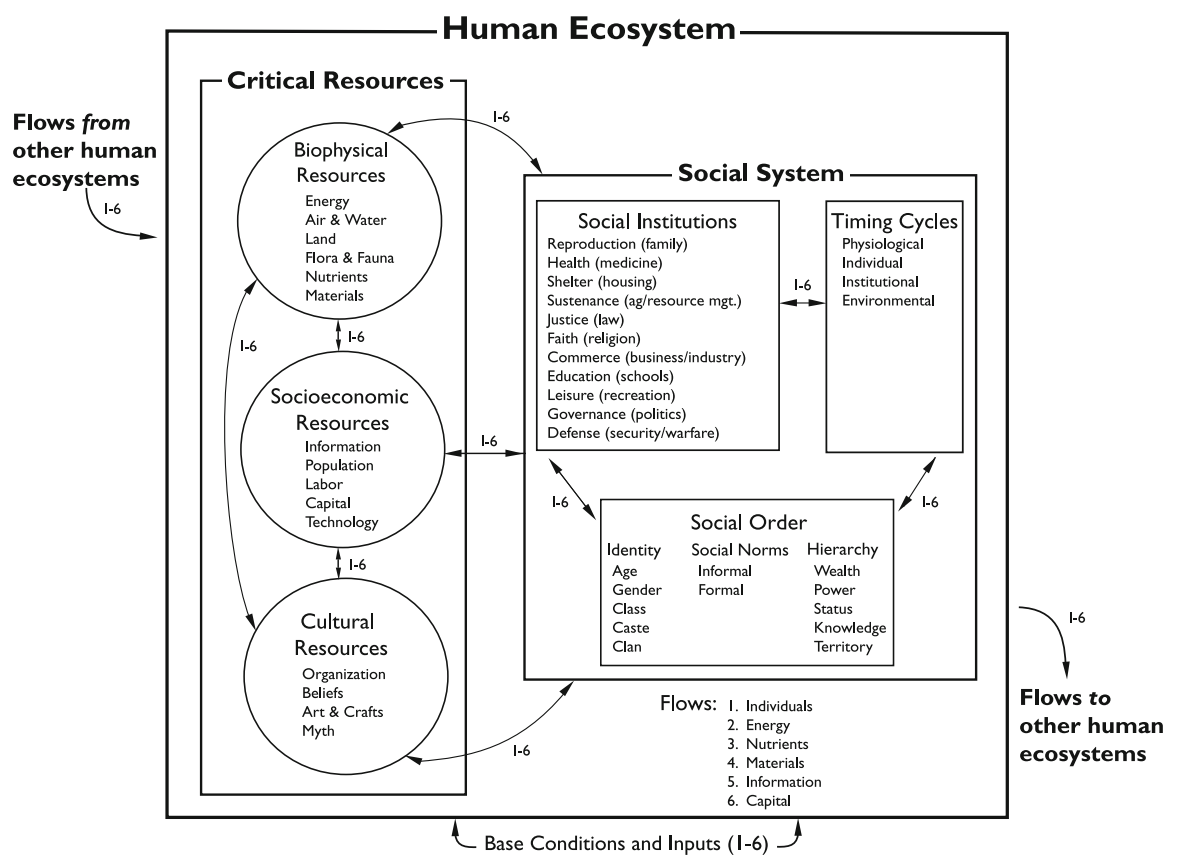

Fig. 3.4 A framework for the coupled human-natural system, showing the interconnectedness of critical resources and the social system is useful for guiding science during environmental crises (Adapted from Machlis et al. 1997)

By necessity, science during crisis is also often conducted by multidisciplinary teams where these teams are often formed quickly in response to the event. For environmental crises, members may represent fields ranging from the physical and natural sciences to human biology and social sciences. These teams are also multi-institutional and include scientists from the academic, government, non-profit, and private sectors. In many cases, the individuals in crisis science teams have not previously worked together before (see Fig. 3.5). Examples include the nuclear physics theorists and weapons engineers of Manhattan Project during WWII, teams of engineers from manufacturer plants and universities working together to solve the Apollo 13 crisis, and academic and federal geoscientists working with oil industry engineers to address the Deepwater Horizon oil spill.

The urgency of the task, compression of time available for research, and lack of previous collaboration can add additional challenges in communication among scientists, as well as issues of trust and collaboration styles. At the same time, a shared and critical mission can promote cooperative behavior and remove traditional barriers to collaboration by establishing common ground, focus upon mission rather than process, and recognition of expertise rather than representation of organizations, institutions, and academic pedigree or rank. 

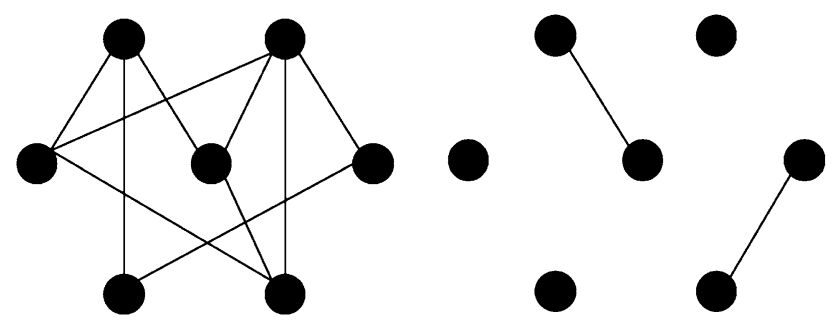

Fig. 3.5 Schematic collaboration patterns of science teams during non-crisis and crisis times. On the left is a schematic network diagram of a science team operating during non-crisis times. Nodes represent individual scientists and links represent previous collaboration (e.g., via co-investigators on a grant proposal or co-authoring a publication). Members of this team have worked with one another before. On the right is a schematic of a crisis science team, showing that only a few of the members have previously collaborated (After Börner 2010, 2011)

\subsubsection{The Importance of Uncertainties and Limitations}

During an environmental crisis, conditions can rapidly change: for example, an earthquake may trigger a tsunami, which may cause a nuclear emergency; evolving weather conditions may intensify an approaching hurricane, divert a storm track, and complicate evacuations. Working with limited knowledge and operating with uncertainty is inherent to responding to - and making decisions during - a crisis. For science during crisis to be useful to decision makers, it is essential to establish and explicitly state levels of uncertainty and knowledge limitations. For example, during the Deepwater Horizon oil spill, multiple studies produced different evaluations for the volume of oil leaking from the broken pipe on the seafloor (McNutt et al. 2012). These assessments had important and immediate implications for determining the best technical solution to capping the wellhead, determining the amount of chemical dispersant to be applied, planning for containment of oil once it reached the surface, and evaluating the extent of damage to the environment (McNutt et al. 2012). Determining and communicating scientific uncertainty with the flow rate estimates was essential to guiding sound decision-making during the spill, and retrospective analysis of these estimates have provided valuable lessons learned for responding to future deep sea blowouts (McNutt et al. 2012).

Similarly, the scenarios built by the DOI Strategic Sciences Group included formal evaluations of scientific uncertainty for each consequence in a chain of consequences; the evaluation (made using expert opinion and following the precautionary principle) was adapted from the Intergovernmental Panel on Climate Change's uncertainty scale associated with climate change, and other scales (see Weiss 2003). 


\subsubsection{The Value of Cascading Consequences and Assessing Impacts}

To be effective during emergency response, recovery, and restoration, science during environmental crises often requires the examination of cascading consequences over both short- and long-term time scales. "Chains of consequences" illustrate changes, effects, or impacts resulting from an event. A chain of consequences begins with an event - such as a major oil spill or hurricane - and branches out, like a flow chart or tree diagram, showing possible cascading events. Each consequence in the chain has the potential to lead to other consequences. Each consequence in the chain can be assigned a level of scientific uncertainty - an assessment used to communicate the certainty or likelihood of a consequence.

Chains of consequences can reveal unanticipated effects of different events. For example, during Hurricane Sandy, storm surge caused severe flooding in homes and businesses across the affected region. In the community of Breezy Point, New York, a flooded electrical system led to fires that destroyed more than 120 homes (New York 1 News 2012), leading to the potential release of lead-based paints and the threat of additional health risks to first responders and the community (Plumlee et al. 2012).

Examining such chains of consequences is an area of science during crisis where strategic science can be extremely valuable. While essential tactical science, such as analyzing contaminated flood sediments from a hurricane or monitoring radioactivity in local water supplies, can be on-going during and after an environmental crisis, strategic science can complement tactical efforts by evaluating the cascading effects of an event across the coupled human-natural system.

This approach is illustrated by the work of the Department of the Interior's (DOI) Strategic Sciences Working Group (SSWG) during the Deepwater Horizon oil spill. The SSWG convened two scenario-building sessions (the first just days after the start of the event, the second while the wellhead had not yet been capped) to build scenarios analyzing the cascading consequences of the spill. Defining boundary conditions such as a flow rate estimate, geographic extent, and time horizons, the SSWG assessed short- and long-term consequences such as the effects of chemical dispersants, damage to wetlands, and impact to the local economy (Department of the Interior 2010, 2012; Machlis and McNutt 2010).

\subsubsection{The Need for Sense of Place}

Every environmental crisis is different from the last or the next: a major earthquake in southern California will require different response than an oil spill in the Gulf of Mexico or a severe tornado in Oklahoma. Even similar crises have place-based differences: an Alaskan Arctic oil spill differs from a Gulf of Mexico oil spill in technology, impacts, response, and restoration/recovery strategies. Depending on where 
and when the crisis occurs and the severity of damage, people in the affected region are impacted differently - the result of factors including geographic location, socioeconomic status, and sociocultural traits. Hence, science during environmental crises must work with an accurate sense of place. Crisis science teams must rely heavily on members with local knowledge who can provide place-specific information on communities, cultures, values, history, and environment that can be essential to assessing risk and responding to unfolding events during a crisis.

\subsubsection{The Demands of Communicating Science During Crisis}

Effectively communicating science is essential if the scientific information is to be used under the rapidly changing conditions, constrained time frames, multiple demands on decision makers, and limited resources that are typical during a crisis. First and foremost, scientific information must be communicated with extraordinary clarity and conciseness. Because the information may be used by non-scientific audiences, technical terms should be well defined if they must be used. Explanation of results, findings, uncertainties and implications must take priority over descriptions of background, relevant literature, or methods.

Communicating science during crisis can also benefit from the use of compelling visualization. An example emerged during the Deepwater Horizon oil spill when graphic artists developed schematic diagrams of the broken pipe on the seafloor. Derived from observations made with remotely operated vehicles, these visualizations aided scientists, responders, decision makers, and the public in understanding the complexity of the damaged riser pipe over 1,500 m below the surface of the Gulf. Presentation tools - ranging from sketchpads to visualization software and mobile tablets - can be useful for translating scientific information quickly and efficiently during a crisis.

To be effective in supporting decision making, science (and scientists) during crisis should have the capacity to speak "truth to power," delivering difficult or unpopular findings or analyses. Direct access to decision-makers is essential. Access requires trust. As shown in many of the previous examples, scientific information can be pivotal for decision making during a crisis. It must be delivered directly to decision makers unfettered by layers of bureaucracy and/or the public diversion of "science by interview" (whereby competing scientists present their personal views to reporters and/or commentators) now fashionable in the contemporary media.

Issues of transparency and public right-to-know are considerable, and must be adjudicated carefully. Post-crisis publication through peer reviewed literature and third-party evaluation are both potential solutions. However, while science during crisis should have access to decision-makers (and vice versa), it is the responsibility of the scientists involved to maintain their independence and credibility and role as "honest brokers" (Pielke 2007) by presenting information rather than attempting to make policy or response decisions. For trust (and thereby access), it is essential that this distinction be maintained in communications between scientists and decision makers during crisis. 


\subsection{A Modest Research Agenda}

Clearly, the application of science during crisis is not novel: it has been used to monitor and respond to events ranging from epidemics and terrorist attacks to manmade disasters and natural hazards. However, there has been little coordinated effort to formally characterize science (including social science) during crisis and to identify ways in which it can be improved for responding to future crisis events. This is particularly true for environmental crises, with the oft-repeated pattern of multiple jurisdictions, overlapping responsibilities, a traditional focus on tactical rather than strategic science, and high levels of uncertainty.

There are ample opportunities for improvement. New organizational frameworks could streamline the use and application of science during crisis. New technologies could improve visualization, communication, and the sharing of information among scientists, emergency responders, and the public. Advanced training, simulations, and workforce development could improve the preparation of the next generation of scientists needed to respond to future crisis events. Preparing decision makers to use science during crises and to make science-informed decisions is equally important.

While the role of science during crises - war, natural disasters, industrial accidents, pandemics, and more - has increased significantly in contemporary times, there has been little scholarly attention devoted to the distinctive character of science during crisis and how such science can most effectively be planned, conducted, examined, communicated, and applied to decision-making. This is particularly true for interdisciplinary and strategic science. Organizational frameworks for science during crisis have not been described, best practices have not been systematically identified (Machlis and McNutt 2011; Machlis and Kooistra 2012), and a research agenda for understanding and improving science during crisis has not been proposed or implemented.

We suggest a modest first step is to examine several essential questions:

1. Is science during crisis different than science practiced in non-crisis periods, and if so, how?

2. If it is different, how do these differences affect the management, design, conduct, analysis, application, and dissemination of science?

3. How can science during crisis be improved and made more useful?

4. How can the workforce and scientific community be better prepared?

5. What are the most appropriate organizational frameworks and best practices for science during crisis?

6. What role can interdisciplinary and strategic science play in responding to major crises?

A range of disciplines including sociology, anthropology, economics, organizational and management science, as well as policy studies can be fruitful partners in answering these questions. Historians of science can provide thoughtful guidance based on the role of science in historical and recent past events. For environmental crises, professionals in hazards management, emergency response, risk assessment, and resources management can be vital contributors, both as end-users of strategic 
sciences and as "first responders" responsible for emergency and recovery. Results should be shared broadly and thoughtfully converted to usable knowledge. The result would be improved science during crisis.

\subsection{Conclusion}

In early 2009, tremors and foreshocks were increasing in the Abruzzo region of central Italy. The swarms of small quakes concerned local citizens, and Italian science technician Giampaolo Giulian was predicting a major quake, only to be reported to the police. A select group of Italian scientists, all members of the National Commission for the Forecast and Prevention of Major Risks, met on March 31, to assess the situation, and decide on a course of action. A press conference was held after the meeting, led by the technical head of Italy's Civil Protection Agency. He announced,

the scientific community tells me there is no danger because there is an ongoing discharge of energy. The situation looks favorable. (Nosengo 2010)

Many citizens of the mountainous region were relieved, and evacuation or precautionary pre-positioning of emergency supplies did not occur.

On April 6 a significant (magnitude 6.3) earthquake epicentered near the town of L'Aquila, the capital of the Abruzzo, struck the region. It was at relatively shallow depth $(8.8 \mathrm{~km})$, and the region's soil structure amplified the seismic impact. Nearly

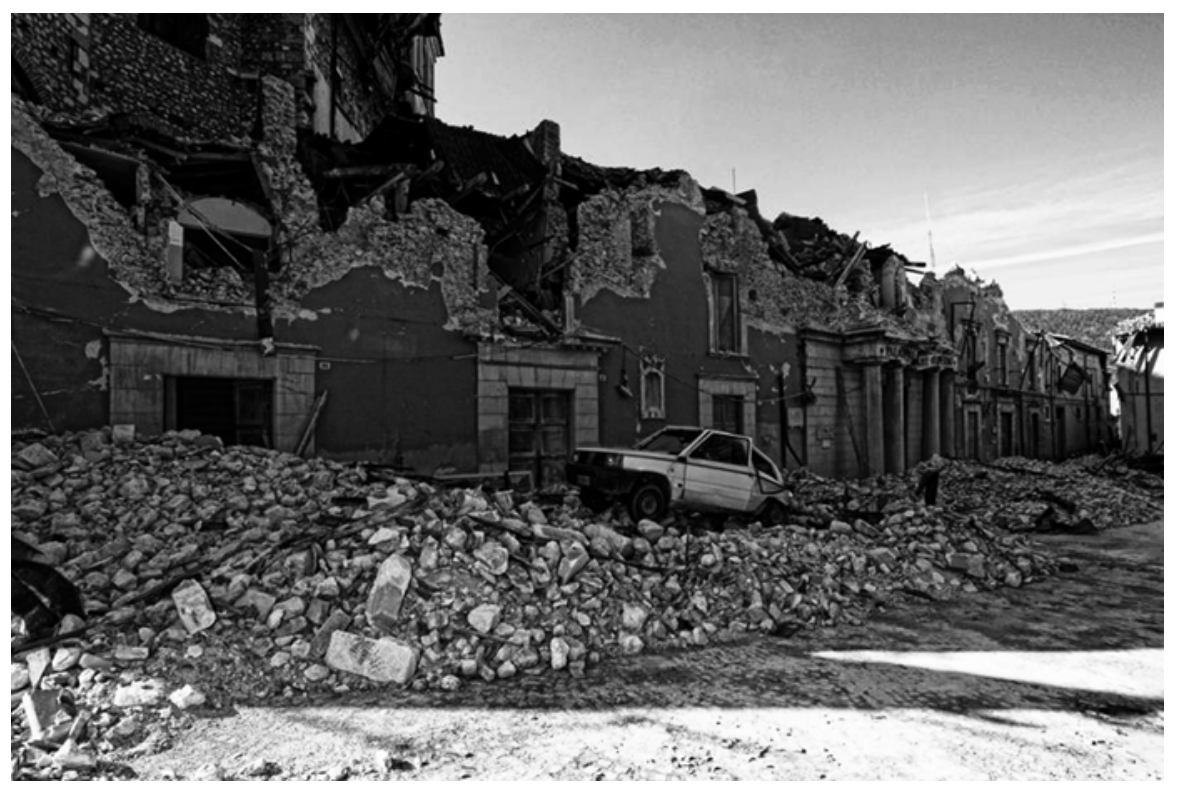

Fig. 3.6 Damage from 2009 L'Aquila Earthquake (Website of the Italian Civil Protection Department - Presidency of the Council of Ministers, http://www.protezionecivile.gov.it/jcms/en/ descrizione_sismico.wp;jsessionid=6EED29F25DA52C422634EE009FC67CAE?pagtab=3) 
$70 \%$ of the buildings in L'Aquila were severely damaged or destroyed (Fig. 3.6). Over 300 persons died, 1,500 were injured, and thousands were left homeless (Kaplan et al. 2010). In a trial watched by the global scientific community with alarm, six of the scientists were convicted of manslaughter, for giving falsely assuring advice on possibility of a major and devastating quake. The convictions are under appeal.

Severe environmental crises disrupt multiple dimensions of social, economic, and environmental systems over both short- and long-term time scales. It is likely that the complexity and impact of such crises will increase as human population continues to rise, technology becomes more complex and vulnerable, climate change acts as a driving force and/or accelerant for many environmental crises, and as local, regional, and national economies become more globalized and interdependent. Fatalities will likely increase in the future due to more people living in hazard-prone areas (e.g., Holzer and Savage 2013). The insurance industry has shown that the cost of property damage from natural hazards is increasing and even single events "can greatly strain a nation's ability to deal with direct damage costs and indirect economic, social, and cultural losses" (American Geosciences Institute 2012).

Because of this growing cost and complexity, it is likely that science will play an increasingly significant role in supporting response to and preparation for future environmental crises. Scientists, emergency managers, business leaders, educators, and local, state, and federal decision makers will have to cooperate to ensure public safety and to develop solutions to mitigating and adapting to risk. Beyond these challenges, the scientific community - including the social sciences and its practitioners - must grapple with the responsibility of science and scientists during crisis, and the implications of events on the island of Martinique and the Italian region of Abruzzo.

Open Access This chapter is distributed under the terms of the Creative Commons Attribution Noncommercial License, which permits any noncommercial use, distribution, and reproduction in any medium, provided the original author(s) and source are credited.

\section{References}

Abramson, D. M., Redlener, I. E., Stehling-Ariza, N. A., Sury, J., Banister, A. N., Park, Y. S. (2010, August). Impact on children and families of the Deepwater Horizon oil spill: Preliminary findings of the Coastal Population Impact Study. National Center for Disaster Preparedness, Research Brief 2010:8.

American Geosciences Institute. (2012, October 17). Critical needs for the twenty-first century: The role of the geosciences [Internet]. Alexandria: American Geosciences Institute. Available from: http://www.agiweb.org/gap/criticalneeds/hazards.html. Accessed 20 Mar 2012.

Blake, E. S., Kimberlain, T. B., Berg, R. J., Cangialosi, J. P., \& Beven, J. L., II. (2013). Tropical cyclone report Hurricane Sandy (AL182012) 22-29 October 2012. Miami: National Hurricane Center.

Börner, K. (2010). Atlas of science: Visualizing what we know. Cambridge, MA: The MIT Press.

Börner, K. (2011). Network science: Theory, tools, and practice. In B. William Sims (Ed.), Leadership in science and technology: A reference handbook. Thousand Oaks: Sage. 
Brown, V. A., Harris, J. A., \& Russell, J. Y. (2010). Tackling wicked problems throughout the transdisciplinary imagination. London: Earthscan.

Coles, J. B., \& Zhuang, J. (2013). Partnership behavior in disaster relief operations: A case study of the response to Hurricane Sandy in New Jersey (Atlantic City, New Jersey, 2013), Field Report, University at Buffalo

Consortium for Ocean Leadership. (2010). Deepwater horizon oil spill: Scientific symposium meeting summary. Washington, DC: Consortium for Ocean Leadership.

Department of Energy. (2012, November 7). Responding to Hurricane Sandy: DOE situation reports [Internet]. Washington, DC: Department of Energy. Available from: http://energy.gov/ articles/responding-hurricane-sandy-doe-situation-reports. Accessed 20 Mar 2013.

Department of the Interior. (2010). DOI Strategic Sciences Working Group Mississippi Canyon 252/Deepwater Horizon oil spill progress report 1, 9 June 2010. Washington, DC: Department of the Interior.

Department of the Interior. (2012). DOI Strategic Sciences Working Group Mississippi Canyon 252/Deepwater Horizon oil spill progress report 2, May, 2012. Washington, DC: Department of the Interior.

Department of the Interior. (2013). DOI Strategic Sciences Group Operational Group Sandy technical progress report. Washington, DC: Department of the Interior.

Fermor, P. L. (1950). The traveler's tree: A journey through the Caribbean Islands. London: John Murray Press.

Freudenburg, W. R., \& Gramling, R. (2011). Blowout in the Gulf: The BP oil spill disaster and the future of energy in America. Cambridge, MA: MIT Press.

Grattan, L. M., Roberts, S., Mahan, W. T., Jr., McLaughlin, P. K., Otwell, W. S., \& Morris, J. G., Jr. (2011). The early psychological impacts of the Deepwater Horizon oil spill on Florida and Alabama communities. Environmental Health Perspectives, 119(6), 838.

Holzer, T. L., \& Savage, J. C. (2013). Global earthquake fatalities and population. Earthquake Spectra, 29(1), 55-175.

Kaplan, H., Bilgin, H., Yilmaz, S., Binici, H., \& Oztas, A. (2010). Structural damages of L'Aquila (Italy) earthquake. Natural Hazards and Earth System Sciences, 10, 499-507.

Kuhn, T. (1962). The structure of scientific revolutions. Chicago: University of Chicago Press.

Lee, M. R., \& Blanchard, T. C. (2012). Community attachment and negative affective states in the context of the BP Deepwater Horizon disaster. American Behavioral Scientist, 56(1), 24-47.

Levy, J., \& Gopalakrishnan, C. (2010). Promoting ecological sustainability and community resilience in the US Gulf Coast after the 2010 Deepwater Horizon oil spill. Journal of Natural Resources Policy Research, 2(3), 297-315.

Lubchenco, J., McNutt, M. K., Dreyfus, G., Murawski, S. A., Kennedy, D. M., Anastas, P. T., Chu, S., \& Hunter, T. (2012). Science in support of the Deepwater Horizon response. Proceedings of the National Academies of Sciences, 109(50), 20212-20221.

Mabus, R. (2010). America's Gulf Coast: A long term recovery plan after the Deepwater Horizon oil spill. Washington, DC: RestoretheGulf.gov.

Machlis, G. E., \& Kooistra, C. (2012). Science during crisis: The DOI strategic sciences group and its OSS inspiration. The OSS Society Journal, Fall, 48-50.

Machlis, G. E., \& McNutt, M. K. (2010). Scenario-building for the Deepwater Horizon oil spill. Science, 329(6007), 1018-1019.

Machlis, G. E., \& McNutt, M. K. (2011). Ocean policy: Black swans, wicked problems, and science during crises. Oceanography, 24(3), 318-320.

Machlis, G. E., Force, J., \& Burch, W. R. (1997). The human ecosystem part I: The human ecosystem as an organizing concept in ecosystem management. Society and Natural Resources, 10(4), 347-367.

McNutt, M. K., Camilli, R., Crone, T. J., Guthrie, G. D., Hsieh, P. A., Ryerson, T. B., Savas, O., \& Shaffer, F. (2012). Review of flow rate estimates of the Deepwater Horizon oil spill. Proceedings of the National Academies of Sciences, 109(50), 20260-20267. 
Millin, M., Jenkins, L., \& Kirsch, T. D. (2006). A comparative analysis of two external healthcare disaster responses following Hurricane Katrina. Prehospital Emergency Care, 10(4), 451-456.

Morris, J. G., Jr., Grattan, L. M., Mayer, B. M., \& Blackburn, J. K. (2013). Psychological responses and resilience of people and communities impacted by the Deepwater Horizon oil spill. Transactions of the American Clinical and Climatological Association, 124, 191.

Nature. (2010). All at sea. Nature, 465, 397-398.

New York 1 News. (2012, December 25). Fire officials determine origin of Breezy Point fire caused by Sandy. [Internet]. New York: NY1.com. Available from: http://www.ny1.com/content/top_ stories/174510/fire-officials-determine-origin-of-breezy-point-fire-caused-by-sandy. Accessed 21 Mar 2013.

NOAA. (2012, October 29). NOAA Hurricane Report 29 [Internet]. Miami: National Hurricane Center. Available from: http://www.nhc.noaa.gov/archive/2012/al18/al182012.discus.029.shtml. Accessed 23 Feb 2013.

Nosengo, N. (2010). Italy puts seismology in the dock. Nature, 465, 992.

Paul, B. K. (2012). Factors affecting evacuation behavior: The case of 2007 Cyclone Sidr, Bangladesh. Professional Geographer, 64(3), 401-414.

Pew Research Center's Project for Excellence in Journalism. (2013). Hurricane Sandy and Twitter.Available from: http://www.journalism.org/index_report/hurricane_sandy_and_twitter. Accessed 5 Sept 2013.

Pielke, R. A., Jr. (2007). The honest broker: Making sense of science in policy and politics. London: Cambridge University Press.

Plumlee, G., Morman, S. A., \& Cook, A. (2012). Environmental and medical geochemistry in urban disaster response and preparedness. Elements, 8(6), 451-457.

Rhodes, R. (1986). The making of the atomic bomb. New York: Simon and Schuster.

Rittel, H. W. J., \& Webber, M. M. (1973). Dilemmas in a general theory of planning. Policy Sciences, 4, 155-169.

Rudel, T. K. (1999). Critical regions, ecosystem management, and human ecosystem research. Society and Natural Resources, 12(3), 257-260.

Sarder, Z. (2000). Thomas Kuhn and the science wars. Cambridge: Icon Books UK.

Sederer, L. (2012, November). FEMA approves $\$ 8.2$ million for post-Sandy mental-health outreach. The Atlantic.

Shen, H. (2012, November 15). Historic Gulf oil spill settlement to bolster US research [Internet]. London: Nature.com. Available from: http://blogs.nature.com/news/2012/11/historic-gulf-oilspill-settlement-to-bolster-us-research.html. Accessed 15 Nov 2012.

Soule, B. (2012). Coupled seismic and socio-political crises: The case of Puerto Aysen in 2007. Journal of Risk Research, 15(1), 21-37.

Taleb, N. N. (2007). The black swan: The impact of the highly improbable. New York: Random House.

US Geological Survey. (2013). Response to Hurricane Sandy [Internet]. Reston: US Geological Survey. Available from: http://coastal.er.usgs.gov/hazard-events/sandy. Accessed 21 Mar 2013.

Vu, L., \& VanLandingham, M. J. (2012). Physical and mental health consequences of Katrina on Vietnamese immigrants in New Orleans: A pre-and post-disaster assessment. Journal of Immigrant and Minority Health, 14(3), 386-394.

Weiss, C. (2003). Expressing scientific uncertainty. Law, Probability, and Risk, 2, 25-46. 